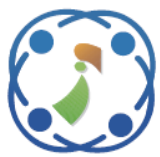

\title{
Influence of Adding BESS as Ancillary Controller of Wind Power Plant on Low Frequency Oscillation
}

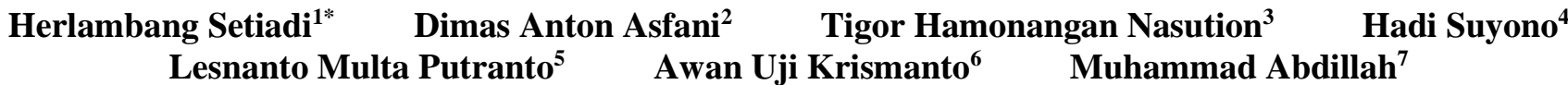 \\ ${ }^{I}$ Department of Advanced Technology, Faculty of Advanced Technology and Multidiscipline, \\ Universitas Airlangga, Surabaya, Indonesia \\ ${ }^{2}$ Department of Electrical Engineering, Faculty of Intelligent Electrical and Informatics Technology, \\ Institut Teknologi Sepuluh Nopember, Surabaya, Indonesia \\ ${ }^{3}$ Department of Electrical Engineering, Engineering Faculty, \\ Universitas Sumatra Utara, Medan, Indonesia \\ ${ }^{4}$ Department of Electrical Engineering, Engineering Faculty, Universitas Brawijaya, Malang, Indonesia \\ ${ }^{5}$ Department of Electrical and Information Engineering, Engineering Faculty, \\ Universitas Gadjah Mada, Yogyakarta, Indonesia \\ ${ }^{6}$ Department of Electrical Engineering, \\ Institut Teknologi Nasional Malang, Malang, Indonesia \\ ${ }^{7}$ Department of Electrical Engineering, Faculty of Industrial Technology, \\ Universitas Pertamina, Jakarta, Indonesia \\ * Corresponding author's Email: h.setiadi@stmm.unair.ac.id
}

\begin{abstract}
This paper introduces the influence on integrating battery energy storage system (BESS) as ancillary controller of wind power plant in small signal stability. Modified two area power system is used as the test system. The modification has been made by replacing one synchronous generator with wind and PV generation. Modal analysis and phase portrait analysis are used to investigate the influence of adding BESS on wind power plant. From the simulation results it is found that the small signal stability performance can be enhance by adding BESS as ancillary controller of wind power plant. This result indicated by increasing damping performance on the critical mode. Furthermore, the oscillatory condition is more damped compared to the base case scenarios. These results indicated by the smallest circular on the phase portrait analysis. Moreover, by adding BESS as ancillary controller the structured singular value (SSV) of the investigated system is 0.8321 . It can be stated that the proposed method is robust against uncertainty (SSV must below 1).
\end{abstract}

Keywords: BESS, Clean energy technology, Oscillatory stability.

\section{Introduction}

Nowadays, the development of renewable based power plant such as wind and solar photovoltaic (PV) is moving very fast. Developed countries such as US, Europe, Australia, Canada and Japan have integrated these renewable based power plant into their existing grid. Likewise, in Indonesia, according to the government regulations the electricity sources in Indonesia must come from $60 \%$ non-renewable sources and $40 \%$ from renewable sources [1]. As a start, Indonesia have integrated $200 \mathrm{MW}$ wind energy conversion system (WECS) into existing grid in Sulselrabar power grid $[2,3]$. The potential of solar power plant in Jawa Island is reported in [4]. As reported from [4], $200 \mathrm{MW}$ of solar power plant in Cirata could be integrated in Jawa-Bali power grid.

Renewable based power plant such as WECS and PV generation could give clean and sustainable energy to the grid. However, they also come with handicap from their sources as well as their way to 
transform natural energy into electricity. Generally, the power output of WECS and PV generation are intermittent due to the uncertainty of their sources. Furthermore, to transform their sources into electricity, WECS and PV generation utilized power electronics devices such as inverter and DC to DC converter. These devices make the WECS and PV generation have inertia-less characteristic as well as different dynamic characteristic. That handicap could bring new challenge in small signal stability of power system. The influence of converter based power plant on small signal stability is reported in [5]. From [5], it was found that due to inertia-less characteristic of converted based power plant, the damping performance of critical modes are deteriorated. Furthermore, different dynamic characteristic is also play important role to change the characteristic of specific modes. The impact of PV generation integration on small signal stability is reported in [6]. As reported in [6], the integration of PV generation could reduce the damping performance of power system. Research effort in [7], shows that uncertainty and inertia-less characteristic of WECS could lead to small signal instability. Not only on small signal stability, the integration of WECS could also bring new challenge on voltage stability as reported in [8]. The influence of WECS integration on transient stability is reported in [9]. From above research, it is important to handle the problem of intermittent power output as well as inertia-less characteristic of renewable based power plant. However, from all the study above, the application of BESS is not considered and not investigated.

To handle the uncertainty power output of WECS and PV generation, the ancillary controller such as battery energy storage system (BESS) is inevitable. BESS could be a solution for handling uncertainty power output of renewable based power plant as they can store electricity. As reported in [10], BESS can be solution to handle uncertainty power flow in renewable based microgrid. Research effort in [11], shows that by adding BESS as additional controller PV generation can be used as dispatchable power plant. BESS could also be used to enhance the frequency stability performance of system as reported in [12]. In [12], BESS is used to enhance the frequency performance of renewable rich microgrid. Furthermore, as reported in [13], BESS also have positive influence on small signal stability. From [13], it was found that adding BESS could enhance the damping performance of power system significantly. Moreover, the influence of BESS on small signal stability in large-scale power plant considering renewable energy is reported in [14]. Voltage stability of power system with renewable energy could be enhance and stabilizer by using BESS as reported in [15]. From all of the research above, it is noticeable that adding BESS could bring positive impact of stability of power system. However, there are no research regarding the influence of BESS as additional controller in WECS, especially in low frequency oscillation. Hence, it is necessary, to add BESS on WECS, not only to make the power plant dispatchable but also to enhance the stability performance of power system.

This paper investigates the influence of BESS as ancillary controller of WECS. In this research, the scenarios are BESS is already installed in WECS doing their job (store and releasing energy to the grid). Furthermore, in this scenario the WECS is categorized as dispatchable power plant. This study can be used as a reference for academia and practitioner for doing the similar research. The rest of the paper is organized as follows: Section 2 is focused on showing the dynamic model of renewable based power plant and BESS for small signal stability analysis. Test system and method for evaluating small signal stability are described in Section 3. Results, discussion, and conclusions are presented in Section 4 and Section 5.

\section{Modelling}

\subsection{Renewable energy model}

In this research, two type of renewable based power plant namely, WECS and PV generation are used. For small signal stability study, all the system has the presented as dynamic model. The dynamic model of PV generation is shown in Fig 1 [16]. As shown in Fig 1, the PV generation is consisting of PI controller dynamic, current converter limiter and converter dynamic $[17,18]$. This model is used when $\mathrm{PV}$ generation is presented as large-scale PV.

Permanent magnet synchronous generator (PMSG) based WECS is used in this paper. The dynamic characteristic of wind turbine, PMSG and the converter controller are considered in this

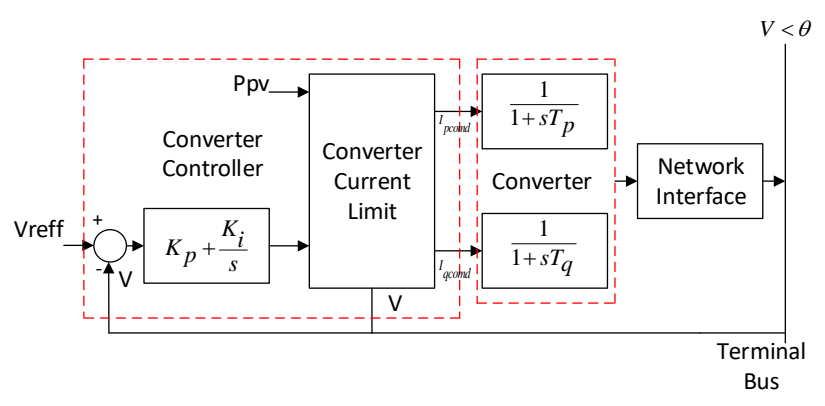

Figure. 1 The dynamic model of large-scale PV generation 


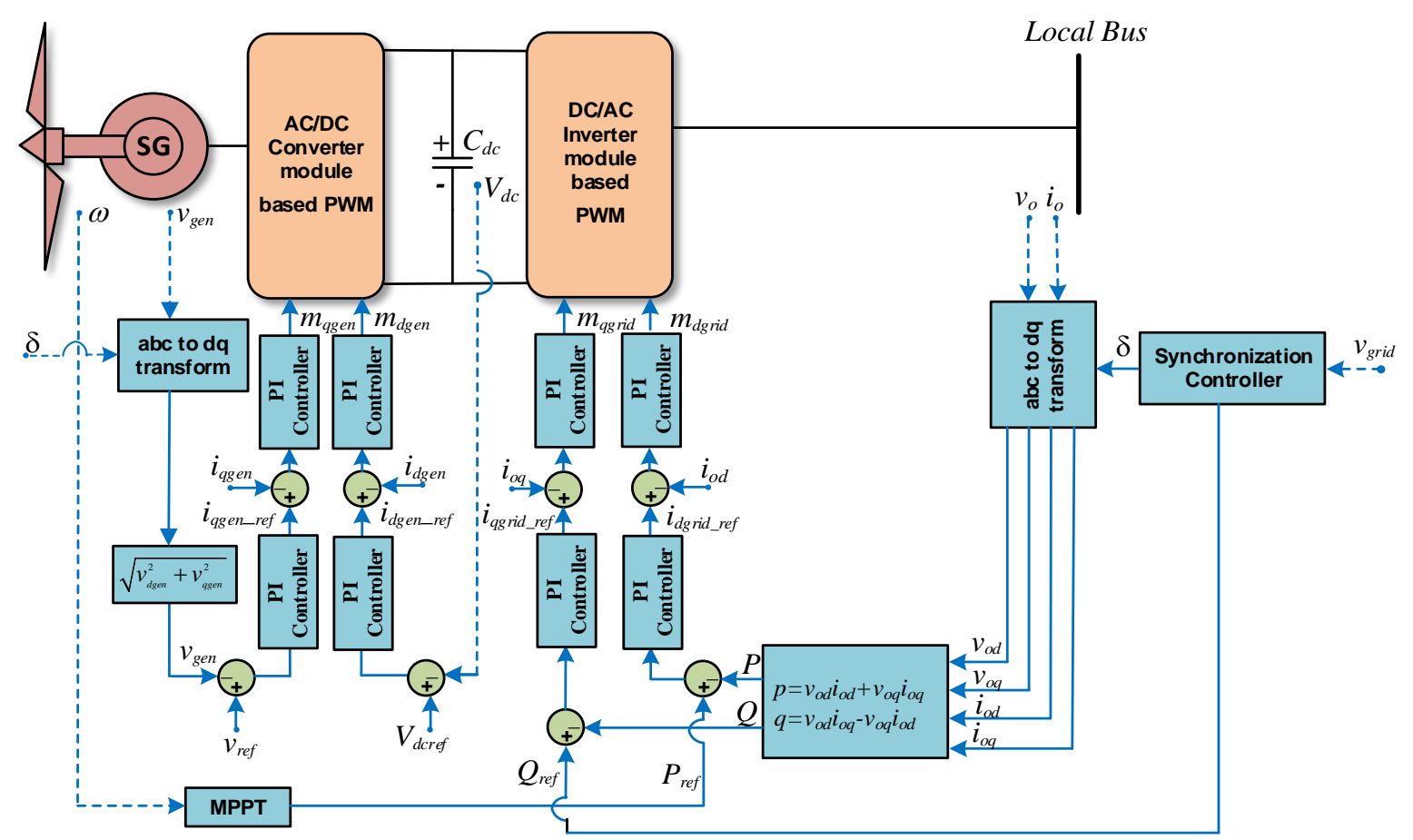

Figure. 2 Dynamic model of WECS based on PMSG

research. By capturing all the dynamic of WECS, the influence of WECS can be captured as similar as in the practical scenarios. The dynamic mode of WECS based on PMSG is depicted in Fig 2 [19]. The aerodynamics of the rotor are presented using Eq. (1) [20-22].

$$
P_{w}=c_{p} \frac{1}{2} \rho A w v_{w}^{3}
$$

Where $P_{w}$ is power extracted from the wind [W]. $c_{p}$ represents power coefficient. Aw denotes area swept by the rotor. While, $\rho$ and $v$ are related to air density $\left[\mathrm{kg} / \mathrm{m}^{3}\right]$ and wind speed upstream of the rotor $[\mathrm{m} / \mathrm{s}]$, respectively. The value of aerodynamic mechanical torque $\left(\tau_{w}\right)$ is determined using Eq. (2) [20-22].

$$
\tau_{w}=\frac{P_{w}}{\omega_{w}}
$$

Where, $\omega_{w}$ is turbine rotor speed. For this research, it is assumed that there is no gearbox system in the WECS. Hence, mechanical torque transmitted to the generator is like aerodynamic torque. The power coefficient can be described as a function of the tipspeed ratio and the blade pitch angle is defined using Eq. (3) [20-22].

$$
c_{p}(\mu, \vartheta)=c_{1}\left(c_{2} \frac{1}{\beta}-c_{3} \vartheta-c_{4} \vartheta^{x w}-c_{5}\right) e^{-c_{6} \frac{1}{\beta}}
$$

Where the coefficient $c_{1}-c_{6}, x w$ are functions of the wind turbine rotor type and $\beta$ which can be described using Eq. (4). In this paper the values of $c_{1}-c_{6}$ and $x w$ are adopted from [20-22].

$$
\frac{1}{\beta}=\frac{1}{\mu+0.08 \vartheta}-\frac{0.035}{1+\vartheta^{3}}
$$

Where $\vartheta$ is the pitch angle of the wind turbine, and the tip ratio $(\mu)$ can be calculated using Eq. (5) [2022].

$$
\mu=\frac{\omega_{w} R}{v_{w}}
$$

The drive train of wind turbine generator system comprises of the rotor shaft, generator, a blade pitching, a hub with the blade. For this work, drive train model can be described using Eq. (6) [20-22].

$$
\frac{d \omega_{g}}{d t}=\frac{\tau_{e}-\tau_{w \_g}}{J_{e q}}-\frac{B_{m}}{J_{e q}} \omega_{g}
$$

Where $\omega_{g}$ is mechanical angular speed of generator. $B_{m}$ corresponds to damping coefficient. $\tau_{w_{-} g}$ represents aerodynamic torque. While $\tau_{e}$, and $J_{e q}$ are electromechanical torque and equivalent inertia, respectively. The sub-index $g$ described the parameter of generator side. The mathematical model of PMSG is given by Eqs. (7), (8) and (9) [2022]. 
$\frac{d_{i d}}{d_{t}}=\frac{1}{L_{d s}+L_{i s}}\left(-R_{s} i_{d}+\omega_{e}\left(L_{q s}+L_{i s}\right) i_{q}+u_{d}\right)$

$\frac{d_{i q}}{d_{t}}=\frac{1}{L_{q s}+L_{i s}}\left(-R_{s} i_{q}+\omega_{e}\left[\left(L_{d s}+L_{i s}\right) i_{q}+\psi_{f}\right]+\right.$

$\left.u_{d}\right)$

$\omega_{e}=p \omega_{g}$

Where, generator parameters correspond to stator resistance $\left(R_{s}\right)$, leakage inductances $\left(L_{i d}, L_{i q}\right)$, generator inductances $\left(L_{d}, L_{q}\right)$, electrical rotating speed $\left(\omega_{e}\right)$, magnetic flux $\left(\psi_{f}\right)$ and some poles $(p)$ are considered in this model. Electromechanical torque equation as dictated in (10) is considered to complete the PMSG model. Moreover, detailed model of WECS based on PMSG can be seen on [20-22].

$\tau_{e}=1.5 p\left(\left(L_{d s}+L_{i s}\right) i_{d} i_{q}+i_{q} \psi_{f}\right)$

\subsection{BESS dynamic representation}

A third-order model of a BESS used in this research was developed by C Liu in 1995 for a load frequency control study [23]. This BESS consists of battery cells, a converter, and its controller scheme. Eq. (11) shows the representation of DC current in battery [24].

$I_{B E S S}=\frac{E_{b t}-E_{b o c}-E_{b 1}}{r_{b t}+r_{b s}}$

Where

$E_{b o c}=\frac{r_{b p}}{1+S T_{b p}} I_{B E S S}$

$E_{b 1}=\frac{r_{b 1}}{1+S T_{b 1}} I_{B E S S}$

$T_{b p}=r_{b p} C_{b p}$

$T_{b 1}=r_{b 1} C_{b 1}$

From Eqs. (11-15) the reactive and active power from BESS could be modeled using Eqs. (16) and (17).

$P_{B E S S}=\frac{3 \sqrt{6}}{\pi} E_{t} I_{B E S}\left(\cos \alpha_{1}+\cos \alpha_{2}\right)$

$Q_{B E S}=\frac{3 \sqrt{6}}{\pi} E_{t} I_{B E S}\left(\sin \alpha_{1}+\sin \alpha_{2}\right)$

In this model, only active power is considered. Hence Eq. (18) can be reduces to Eq (20).

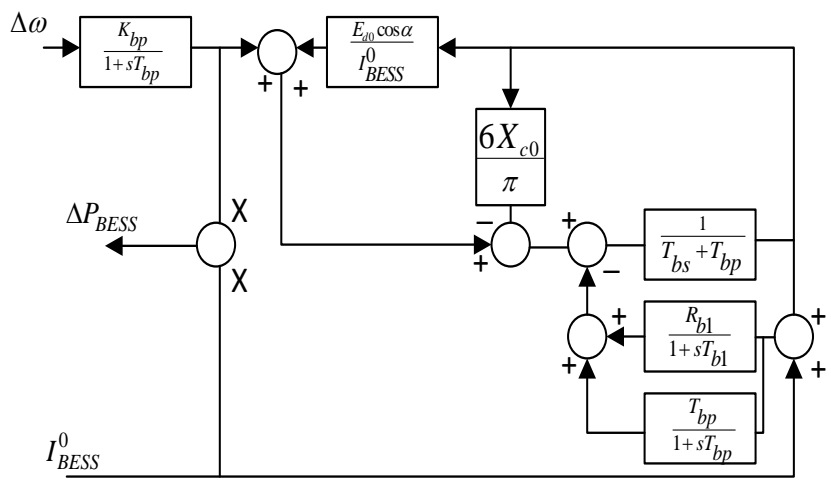

Figure. 3 Diagram block third-order of BESS

Furthermore, damping signals $\Delta \mathrm{E}_{d}$ can be rewritten using Eq. (21).

$P_{B E S S}=\frac{3 \sqrt{6}}{\pi} E_{t} I_{B E S} \cos \alpha$

$Q_{B E S S}=0$

$P_{B E S S}=I_{B E S S}^{0} \Delta \mathrm{E}_{d}$

$\Delta \mathrm{E}_{d}=\frac{K_{b}}{1+S T_{b}} \Delta f$

Eqs (18-21) can be further represented as a block diagram shown in Fig. 3.

\section{Method}

\subsection{Test system}

In this study, two-area power system is used to investigate the impact of adding BESS as ancillary controller. To perform low inertia condition, a modification has been made to the system. This modification is conducted by replacing one conventional power plant in area 1 with renewable based power plant. The renewable based power plant consists of $350 \mathrm{MW}$ aggregated PV generation and wind power plant. Furthermore, $60 \mathrm{kWh}$ BESS is installed in wind power plant as ancillary service. PV and wind power plant are completely modelled with the converter and the associate controller. Hence, the system consists of three conventional power plant and two renewable based power plant as shown in Fig. 4. All the dynamic model of this study is based on the generic model from IEEE and WECC standard. Furthermore, all the data (load flow and dynamic data) are based on the real and practical data of Two Area Power System.

To identify the influence of BESS as ancillary services, eigenvalue and damping of electromechanical modes are performed. To validate 


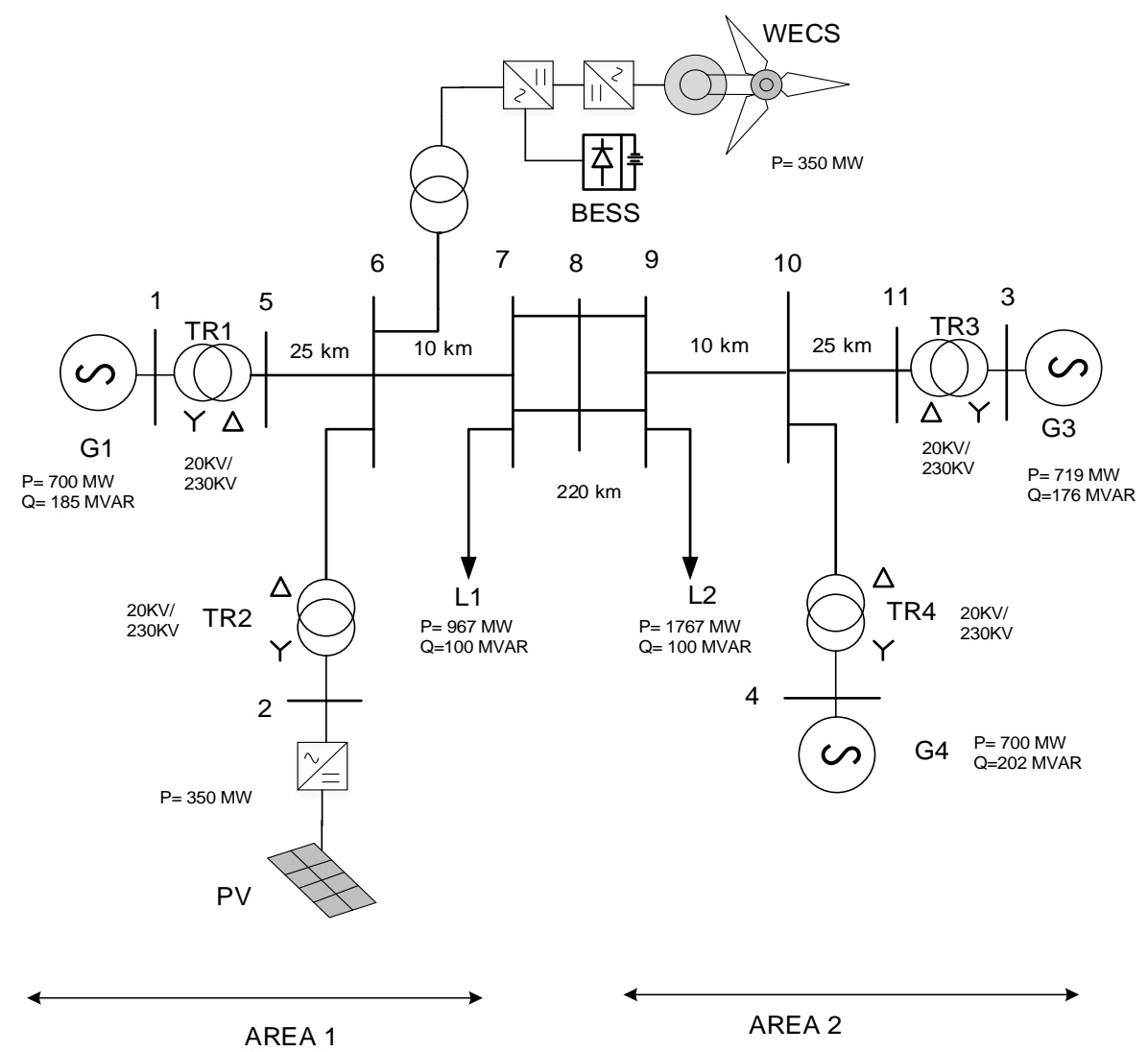

Figure. 4 Two area power system with renewable based power plant

the modal analysis, phase portrait investigation is conducted. Moreover, increasing the load demand of the system is simulated to investigate how much load demand can be enhanced by installing a small BESS in WECS.

\subsection{Small signal stability}

In the study of small signal stability damping torque and stable synchronization are essential to maintain the small signal stability. Low-frequency oscillation can be classified as a local (with the frequency oscillation around 0.7 to $2 \mathrm{~Hz}$ ) or global mode or inter-area mode (frequency oscillation ranging from 0.1 to $0.7 \mathrm{~Hz}$ ) [25]. For small signal stability study linearized equation of nonlinear algebraic and differential equation (DAE) is used to represent of power system. A nonlinear mathematical model of the power system can be captured by Eq. (22) and (23) [25].

$$
\begin{aligned}
& \dot{x}=f(x, y, l, p) \\
& 0=g(x, y, l, p)
\end{aligned}
$$

The network and the load flow are calculated using algebraic equation, while machines and their associated controllers are represented in the differential equations. Furthermore, eigenvalue analysis is the key to investigate the oscillatory stability performance of power system. State space approach is used to calculate the eigenvalue of the system at some operating condition. Eq. (24) and (25) are the state space representation of the investigated system by linearizing Eq. (22) and (23) [26].

$$
\begin{aligned}
& \Delta \dot{x}=A \Delta x+B \Delta u \\
& \Delta y=C \Delta x+D \Delta u
\end{aligned}
$$

Eq. (24) and (25) can be further reduced by using Eq. (26) and (27) [27].

$$
\begin{gathered}
A_{s y s}=\left(A-B J_{A E}^{-1} C\right) \\
J_{A E}=\left[\begin{array}{ll}
D_{11} & D_{12} \\
D_{21} & J_{L F}
\end{array}\right]
\end{gathered}
$$


The eigenvalues of the system can be calculated using Eq. (28) [28]. Moreover, complex eigenvalue in Eq. (29) carry an information of frequency oscillation and damping value. Both parameters can be calculated using Eqs. (30) and (31).

$$
\begin{aligned}
& \operatorname{det}\left(\lambda \boldsymbol{I}-\boldsymbol{A}_{\text {sys }}\right)=0 \\
& \lambda_{i}=\sigma_{i} \pm j \omega_{i} \\
& f_{i}=\frac{\omega_{i}}{2 \pi}(H z) \\
& \xi=\frac{\sigma_{i}}{\sqrt{\sigma_{i}^{2}+\omega_{i}^{2}}}
\end{aligned}
$$

\section{Results and discussions}

\subsection{Modal analysis}

In this section, damping ratio and eigenvalue of the critical electromechanical mode are investigated thoroughly. Eigenvalue of critical electromechanical modes are presented in Table 1. It is found that by simulating renewable rich power system condition the eigenvalue of three electromechanical modes are move toward right half plane. This condition indicated that the system have more oscillation condition. Moreover, it is noticeable that when BESS is integrated at WECS the eigenvalue of three electromechanical modes are move toward left half plane. This condition indicated that the small signal stability of power system is enhanced. Fig. 5 shows the damping performance of the eigenvalues of critical electromechanical modes. It is noticeable that the damping performance of system with BESS

\begin{tabular}{|c|c|c|c|}
\hline \multirow{2}{*}{ Cases } & \multicolumn{3}{|c|}{ Critical modes } \\
\hline & Local 1 & Local 2 & Inter-Area \\
\hline $\begin{array}{l}\text { Conventio } \\
\text { nal system }\end{array}$ & $\begin{array}{l}- \\
0.3248 \pm 6.75 \\
77 \mathrm{i}\end{array}$ & $\begin{array}{l}- \\
0.3407 \pm 7.01 \\
83 \mathrm{i}\end{array}$ & $\begin{array}{l}- \\
0.068 \pm 2.60 \\
88 \mathrm{i}\end{array}$ \\
\hline $\begin{array}{l}\text { With } \\
\text { renewable } \\
\text { energy }\end{array}$ & $\begin{array}{l}- \\
0.2828 \pm 6.58 \\
23 \mathrm{i}\end{array}$ & $\begin{array}{l}- \\
0.3410 \pm 7.01 \\
14 \mathrm{i}\end{array}$ & $\begin{array}{l}- \\
0.032 \pm 3.02 \\
47 \mathrm{i}\end{array}$ \\
\hline $\begin{array}{l}\text { With } \\
\text { BESS }\end{array}$ & $\begin{array}{l}- \\
1.1998 \pm 6.38 \\
1 \mathrm{i}\end{array}$ & $\begin{array}{l}- \\
0.3393 \pm 7.01 \\
51 \mathrm{i}\end{array}$ & $\begin{array}{l}- \\
0.724 \pm 3.12 \\
61 \mathrm{i}\end{array}$ \\
\hline
\end{tabular}
installed at WECS provide the best damping performance compared to all scenarios. It should be

Table 1. Modal comparison of different scenarios.

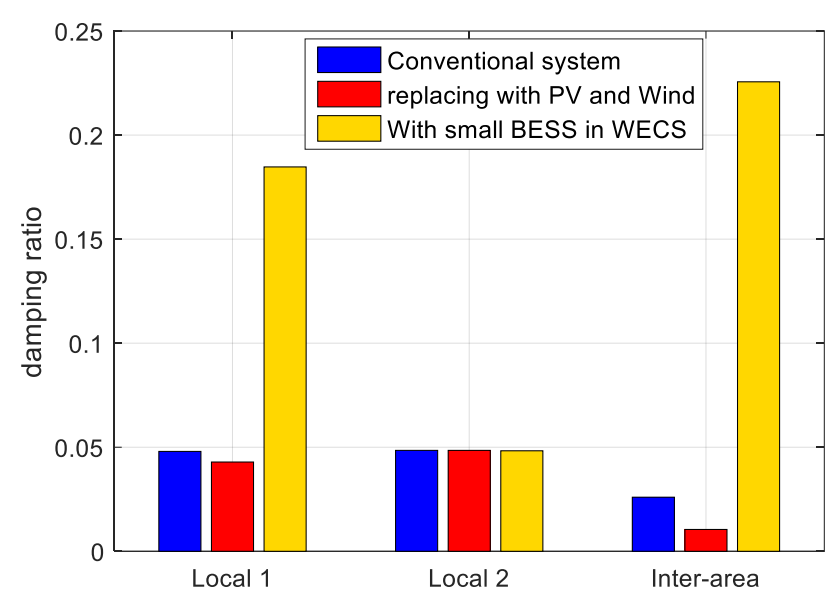

Figure. 5 The damping comparison of investigated system

noted the conventional system in this study is base condition of two area power system.

The phase portrait representation is carried out to validate and verify the eigenvalue and damping results. 0.05 step input of small perturbation is used to excite the weak mode in the system. The phase

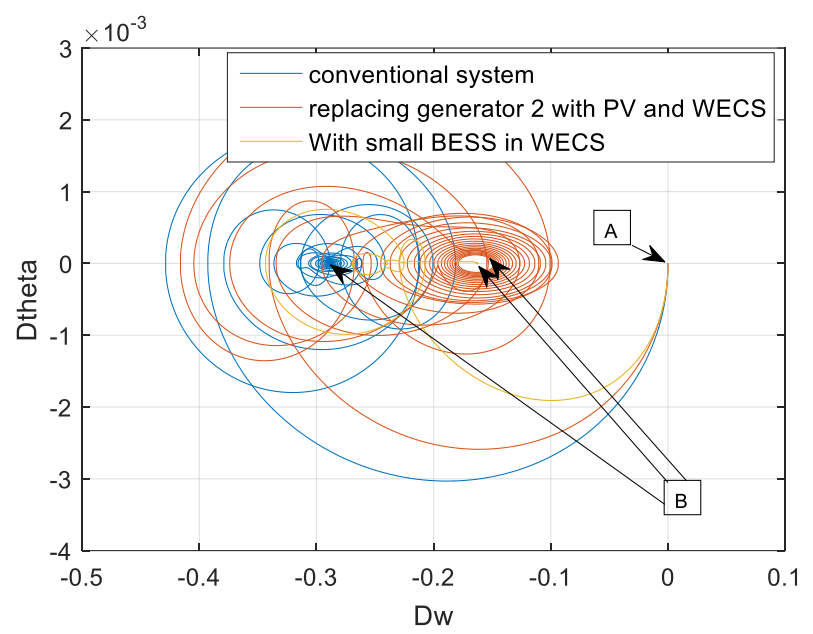

Figure. 6 Phase portrait for generator 1

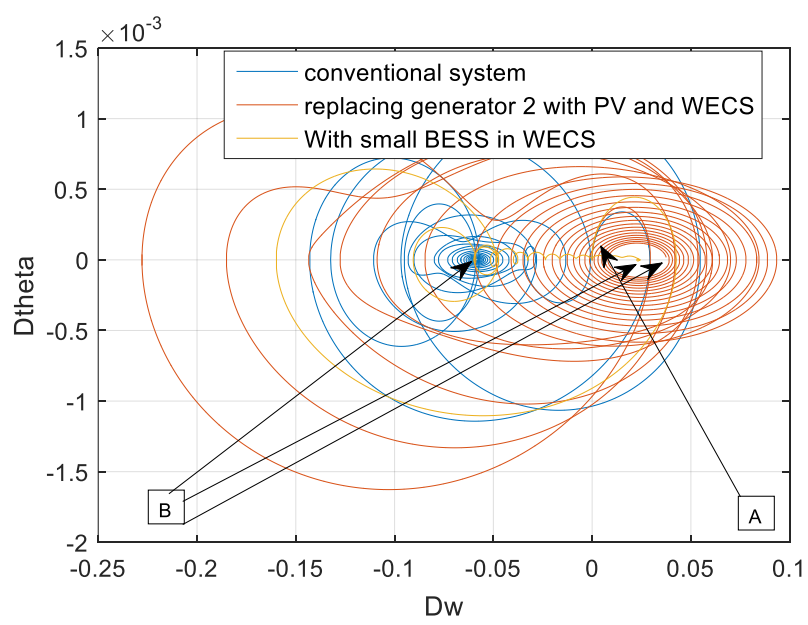

Figure. 7 Phase portrait for generator 3 


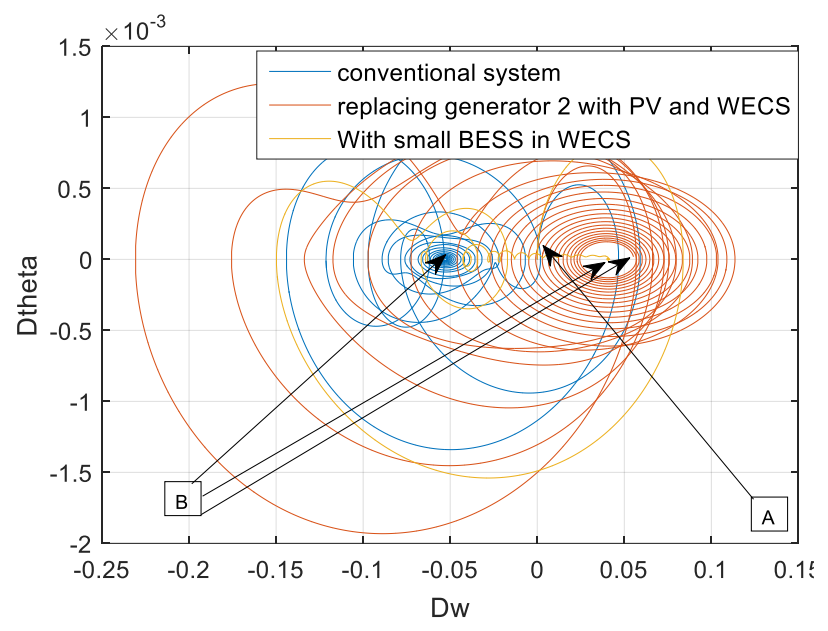

Figure. 8 Phase portrait for generator 4

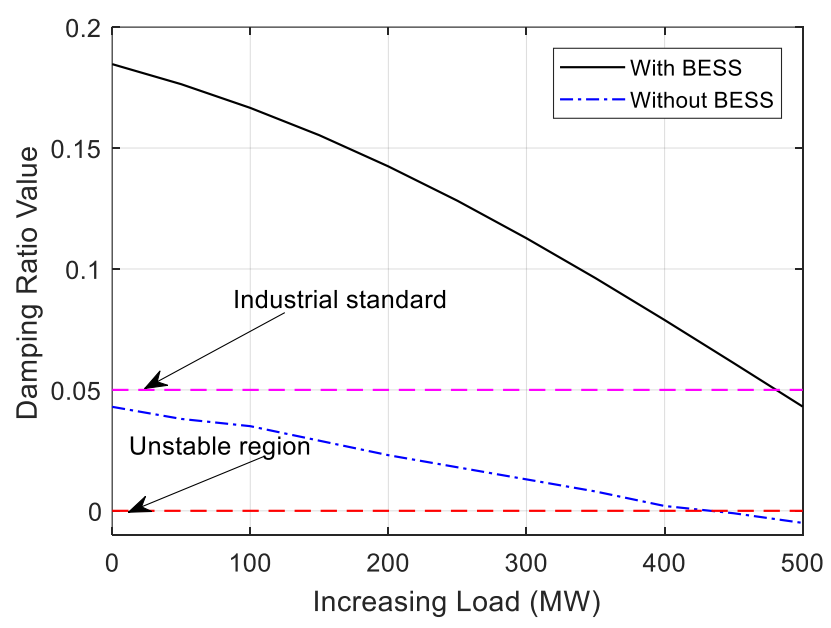

Figure. 9 Damping response to the load demand fluctuation

portrait between rotor speed and rotor angle of generators 1,3 and 4 are depicted in Figs. 6-8. A point is representing the initial condition of generator oscillatory condition, while point $\mathrm{B}$ is presented the steady state condition of generators oscillatory condition. It is observed that the less damping ratio indicated by more circular condition on the phase portrait figure. Furthermore, the best condition is shown by yellow line (WECS with BESS) indicated by less circular condition. Hence, this phase portrait analysis is validated the modal analyst.

\subsection{Impact of increasing load demand}

In this section, investigation on how the performance of the investigated system when the load demand is increased. The load is increased from 50 MW to $500 \mathrm{MW}$ in steps of $50 \mathrm{MW}$. The change in damping performance of local area 1 is investigated to analyze the impact of load demand on oscillatory

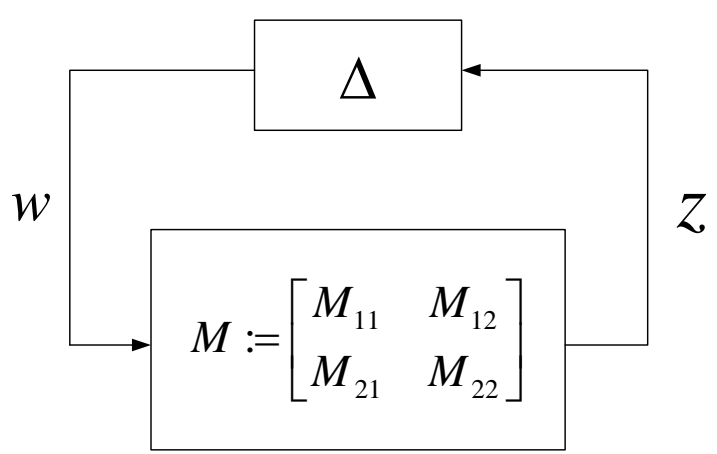

Figure. 10 Structure for robust stability analysis

stability. Investigation of the damping performance of local mode 2 is not conducted because there is no impact on the local mode 2 damping performance due to the proximity of WECS and BESS. Fig. 9 illustrates the damping fluctuation due to the variation of load demand.

It is found that for the local mode of area 1, the damping performance becomes critical when load demand is increased by more than $450 \mathrm{MW}$. Hence, to comply with industry requirements the load demand cannot be increased more than $450 \mathrm{MW}$. Furthermore, the system without a BESS becomes unstable when load demand is increased by more than $400 \mathrm{MW}$.

\subsection{Robustness against uncertainty}

It is noticeable that renewable based power plant provides intermittent power output. Hence, it is essential to test the performance of the investigated system against uncertainty of renewable based power plant. To test the robustness of the system, structured singular value (SSV) can be used. The general technique for robustness assessment using the linear fractional transformation (LFT) is given in Fig 10, where $\mathrm{M}$ indicates the complex transfer matrix as described in Eq. (32) [29].

$M=\left[\begin{array}{ll}M_{11} & M_{12} \\ M_{21} & M_{21}\end{array}\right] \epsilon C^{\left(p_{1}+p_{2}\right) x\left(q_{1}+q_{2}\right)}$

In (32), $\Delta \epsilon C^{\left(p_{1}+p_{2}\right) x\left(q_{1}+q_{2}\right)}$ is another complex matrix. Moreover, $\mathrm{w}$ and $\mathrm{z}$ are the vectors of perturbation output and vector perturbation input. The upper LFT with respect to $\Delta$ can be described in Eq. (33) [29].

$F_{u}(M, \Delta):=M_{22}+M_{21} \Delta\left(I-M_{11} \Delta\right)^{-1} M_{12}$

In Eq. (33), the unperturbed system and the nominal transfer matrix knowledge due to perturbation are described as $\mathrm{M}_{22}, \mathrm{M}_{12}, \mathrm{M}_{11}$, and $\mathrm{M}_{21}$, 
Table 2. Robustness investigation results

\begin{tabular}{|l|l|}
\hline System configuration & $\boldsymbol{\mu}$ Upper bound \\
\hline Without BESS & 1.0341 \\
\hline With BESS & 0.8321 \\
\hline
\end{tabular}

while $\Delta$ is the perturbation. Furthermore, all sources of uncertainties can be denoted by a transfer matrix of $\Delta$. The mathematical representation of $\Delta$ can be presented in Eq. (22) [29].

$$
\Delta=\left\{\operatorname{diag}\left[\delta_{1} I_{r 1}, \ldots \ldots \ldots \delta_{s} I_{r s}, \Delta_{1}, \ldots \ldots \Delta_{F}\right]\right\}
$$

In Eq. (34), the number of full blocks, repeated scalar block, and identity matrix are denoted by $\Delta_{F}, \delta_{s}$ and $I_{r s}, \delta_{s} \in R, \Delta_{s} \in C^{m_{x} x m_{s}}$ [29]. Moreover, the smallest structured uncertainty $\Delta$ is defined as SSV. Furthermore, the SSV or $\mu$ can be expressed as in Eq. (23).

$\mu(M)^{-1}:=\min \{\bar{\sigma}(\Delta): \Delta \epsilon, \operatorname{det}(1-M \Delta)=0\}$

In Eq. (35), $\mu(M)$ determines the robustness of the system. Based on LFT, the system can be stated as the robustly stable system if and only if $\max \mu(M)<$ 1 [29]. The following steps briefly describe the SSV analysis in power system:

Step 1: Linearize the nonlinear system around the chosen operating points.

Step 2: Define the uncertainty (could be a number of the different operating condition, penetration level of REG etc.).

Step 3: Define $A$ matrix which varies with different uncertainty by a certain interval.

Step 4: Define $\delta_{s}$ that will also vary within the interval of different uncertainty. Hence the $\delta_{s}$ can be used to capture the variation of uncertainty.

Step 5: Calculate the $\Delta$ by using Eq. 34 .

Step 6: Calculate $F_{u}(M, \Delta)$ by using Eq. 33 .

Step 7: Calculate $\mu(M)$ by using Eq. 35 .

The details about the SSV calculation can be found in [30] and the references therein.

Table 2 illustrates the robust stability assessment results with the proposed controller. Based on the SSV standard the system can be categorized as robustly stable if the $\mu$-upper bound is less than 1 . It can be seen from Table 5 that the system with the proposed controller has $\mu$-upper bond less than 1 . Hence, according to the SSV theory, the system is robustly stable with the proposed controller.

\section{Conclusions}

This paper focused on investigating the influence of adding BESS as ancillary controller on WECS.
From simulation results it is found that by adding BESS on WECS, the damping performance of the weak modes can be enhanced significantly. It can be seen from the simulation results the damping is increased more than $100 \%$ from the conventional system. From the phase portrait results, by adding BESS on WECS the circular condition is minimum compared to the other scenarios. Moreover, by adding BESS, the uncertainty condition of renewable based power plant can be handled indicated by the SSV value is less than 1 .

\section{Conflicts of interest}

The authors declare no conflict of interest."

\section{Author contributions}

"Conceptualization, Herlambang Setiadi, Dimas Anton Asfani, Tigor Hamonangan Nasution; methodology, Herlambang Setiadi, Hadi Suyono, Lesnanto Multa Putranto; Herlambang Setiadi, Awan Uji Krismanto and Muhammad Abdillah; validation, Herlambang Setiadi, Dimas Anton Asfani, Tigor Hamonangan Nasution, Hadi Suyono, Lesnanto Multa Putranto; format analysis, Awan Uji Krismanto, Muhammad Abdillah and Herlambang Setiadi; investigation, Herlambang Setiadi, Dimas Anton Asfani, Tigor Hamonangan Nasution, Hadi Suyono, Lesnanto Multa Putranto; resources, Herlambang Setiadi; writing original draft preparation, Herlambang Setiadi; writing review and editing Herlambang Setiadi, Awan Uji Krismanto, Muhammad Abdillah, Lesnanto Multa Putranto, Hadu Suyono; visualization, Herlambang Setiadi, Dimas Anton Asfani, Lesnanto Multa Putranto. All authors have read and agreed to the published version of the manuscript".

\section{Appendix}

Table 3. List of notations used in this paper

\begin{tabular}{|l|l|}
\hline Symbol & Meaning \\
\hline$T_{b}$ & time constant \\
\hline$E_{d o}$ & $\begin{array}{l}\text { maximum DC voltage of } \\
\text { batteries }\end{array}$ \\
\hline$E_{b 1}$ & battery overvoltage, \\
\hline$I_{B E S}$ & DC current through battery \\
\hline$y$ & Algebraic variables \\
\hline$\Delta x$ & Vector of state variables \\
\hline$r_{b S}$ & battery internal resistance \\
\hline$r_{b p}$ & self-discharge resistance \\
\hline$r_{b 1}$ & overvoltage resistance \\
\hline$\Delta f$ & frequency deviation \\
\hline$X_{c o}$ & commutating resistance \\
\hline$K_{b}$ & control loop gain \\
\hline$P_{B E S}$ & $\begin{array}{l}\text { active power from the } \\
\text { battery }\end{array}$ \\
\hline
\end{tabular}




\begin{tabular}{|c|c|}
\hline$r_{b t}$ & connecting resistance \\
\hline$\alpha$ & firing angle \\
\hline$x$ & State variables \\
\hline$\Delta u$ & Input vector \\
\hline$J_{L F}$ & Load flow jacobian \\
\hline$\Delta y$ & $\begin{array}{l}\text { Vector of algebraic } \\
\text { variables }\end{array}$ \\
\hline$E_{b t}$ & $\begin{array}{l}\text { average DC voltage of } \\
\text { battery }\end{array}$ \\
\hline$E_{\text {boc }}$ & $\begin{array}{l}\text { the battery open circuit } \\
\text { voltage }\end{array}$ \\
\hline$A$ & Plant matrix \\
\hline$B$ & Control matrix \\
\hline$C$ & Output matrix \\
\hline$D$ & Feedforward matrix \\
\hline$I$ & Identity matrix \\
\hline$\lambda$ & Eigenvalue \\
\hline$f$ & Frequency oscillation \\
\hline$\xi$ & Damping ratio \\
\hline$P_{w}$ & $\begin{array}{l}\text { Power extracted from the } \\
\text { wind }\end{array}$ \\
\hline$c_{p}$ & Power coefficient \\
\hline$A w$ & Area swept by rotor \\
\hline$\rho$ & Air density \\
\hline$v$ & $\begin{array}{l}\text { Wind speed upstream of the } \\
\text { rotor }\end{array}$ \\
\hline$\tau_{w}$ & $\begin{array}{l}\text { Aerodynamic mechanical } \\
\text { torque }\end{array}$ \\
\hline$\omega_{w}$ & Turbine rotor speed \\
\hline$\vartheta$ & Pitch angle wind turbine \\
\hline$\mu$ & Tip ratio \\
\hline$\omega_{g}$ & $\begin{array}{l}\text { Mechanical angular speed } \\
\text { of generator }\end{array}$ \\
\hline$B_{m}$ & Damping coefficient \\
\hline$\tau_{w_{-} g}$ & Aerodynamic torque \\
\hline$\tau_{e}$ & Electromechanical torque \\
\hline$J_{e q}$ & Equivalent inertia \\
\hline$g$ & Parameter of generator side \\
\hline$R_{s}$ & Stator resistance \\
\hline$L_{i d}, L_{i q}$ & Leakage inductances \\
\hline$L_{d}, L_{q}$ & Generator inductances \\
\hline$\omega_{e}$ & Electrical rotating speed \\
\hline$\psi_{f}$ & Magnetic flux \\
\hline$p$ & Poles \\
\hline
\end{tabular}

\section{Acknowledment}

The Authors is very grateful to Universitas Airlangga, Institut Teknologi Sepuluh Nopember and Universitas Sumatra Utara for funding this research through Program Penelitian Kolaborasi Indonesia (PPKI) grant (grant number:170/UN3.15/PT/2021).

\section{References}

[1] H. Setiadi, N. Mithulananthan, R. Shah, T. Raghunathan, and T. Jayabarathi, "Enabling resilient wide-area POD at BESS in Java, Indonesia $500 \mathrm{kV}$ power grid", IET Gener. Transm. Distrib., Vol. 13, No. 16, pp. 3734 3744, 2019.

[2] F. Azis and A. N. Parawangsa, "Analisis Dampak Intermittensi PLTB Berbasis Doubly Fed Induction Generator (DFIG) Terhadap Sistem Kelistrikan Terinterkoneksi Sulselbar", Logitech Tek. Elektro, Vol. 2, No. 1, pp. 50-52, 2019.

[3] I. P. Riasa, R. S. Hartati, I. B. G. Manuaba, and D. A. S. Santiari, "Pengaruh PLTB Sidrap Terhadap Sistem Kelistrikan Sulawesi Selatan", Maj. Ilm. Teknol. Elektro, Vol. 19, No. 1, pp. 27-32.

[4] L. M. P. E Al, "Wind and Solar Power Plant Modelling and Its Impact to the Jawa-Bali Power Grid", In: Proc. of 2018 IEEE PES Asia-Pacific Power and Energy Engineering Conference (APPEEC), pp. 274-279, 2018.

[5] J. Quintero, V. Vittal, G. T. Heydt, and H. Zhang, "The Impact of Increased Penetration of Converter Control-Based Generators on Power System Modes of Oscillation", IEEE Trans. Power Syst., Vol. 29, No. 5, pp. 2248-2256, 2014, doi: 10.1109/TPWRS.2014.2303293.

[6] S. Eftekharnejad, V. Vittal, G. T. Heydt, B. Keel, and J. Loehr, "Small Signal Stability Assessment of Power Systems With Increased Penetration of Photovoltaic Generation: A Case Study", IEEE Trans. Sustain. Energy, Vol. 4, No. 4, pp. 960-967, 2013.

[7] Z. Wang, C. Shen, and L. Feng, "Probabilistic Analysis of Small Signal Stability for Power Systems With High Penetration of Wind Generation", IEEE Trans. Sustain. Energy, Vol. 7, pp. 1-12, Mar. 2016, doi: 10.1109/TSTE.2016.2532359.

[8] B. B. Adetokun, C. M. Muriithi, and J. O. Ojo, "Voltage stability assessment and enhancement of power grid with increasing wind energy penetration", Int. J. Electr. Power Energy Syst., Vol. 120, p. 105988, 2020.

[9] Z. Yue, Y. Liu, Y. Yu, and J. Zhao, "Probabilistic transient stability assessment of power system considering wind power uncertainties and correlations", Int. J. Electr. Power Energy Syst., Vol. 117, p. 105649, 2020.

[10] M. Farrokhabadi, S. Koenig, C. A. Canizares, K. Bhattacharya, and T. Leibfried, "Battery Energy Storage System Models for Microgrid Stability Analysis and Dynamic Simulation", IEEE Transactions on Power Systems, Vol. PP, No. 99. p. 1, 2017, doi: 10.1109/TPWRS.2017.2740163. [11] D. Q. Hung, N. Mithulananthan, and R. C. 
Bansal, "Integration of PV and BES units in commercial distribution systems considering energy loss and voltage stability", Appl. Energy, Vol. 113, pp. 1162-1170, 2014, doi: https://doi.org/10.1016/j.apenergy.2013.08.069.

[12] T. Kerdphol, K. Fuji, Y. Mitani, M. Watanabe, and Y. Qudaih, "Optimization of a battery energy storage system using particle swarm optimization for stand-alone microgrids", Int. J. Electr. Power Energy Syst., Vol. 81, pp. 32-39, 2016, doi: https://doi.org/10.1016/j.ijepes.2016.02.006.

[13] H. Setiadi, N. Mithulananthan, and M. J. Hossain, "Impact of battery energy storage systems on electromechanical oscillations in power systems", In: Proc. of 2017 IEEE Power \& Energy Society General Meeting, pp. 1-5, 2017, doi: 10.1109/PESGM.2017.8274052.

[14] H. Setiadi, A. U. Krismanto, N. Mithulananthan, and M. J. Hossain, "Modal interaction of power systems with high penetration of renewable energy and BES systems", Int. J. Electr. Power Energy Syst., Vol. 97, pp. 385-395, 2018.

[15] Y. Zhang, Y. Xu, H. Yang, and Z. Y. Dong, "Voltage regulation-oriented co-planning of distributed generation and battery storage in active distribution networks", Int. J. Electr. Power Energy Syst., Vol. 105, pp. 79-88, 2019, doi: https://doi.org/10.1016/j.ijepes.2018.07.036.

[16] K. Clark, N. W. Miller, and R. Walling, "Modeling of GE solar photovoltaic plants for grid studies", Gen. Electr. Int. Inc, Schenectady, NY, Vol. 12345, 2010.

[17] R. Shah, N. Mithulananthan, and K. Y. Lee, "Large-scale PV plant with a robust controller considering power oscillation damping", IEEE Trans. Energy Convers., Vol. 28, No. 1, pp. 106-116, 2012.

[18] M. Khayyatzadeh and R. Kazemzadeh, "Subsynchronous resonance damping using high penetration PV plant", Mech. Syst. Signal Process., Vol. 84, No. Part A, pp. 431-444, 2017, doi: https://doi.org/10.1016/j.ymssp.2016.07.023.

[19] A. U. Krismanto, N. Mithulananthan, and O. Krause, "Stability of Renewable Energy based Microgrid in Autonomous Operation", Sustain. Energy, Grids Networks, Vol. 13, pp. 134-147, 2018 , doi: https://doi.org/10.1016/j.segan.2017.12.009.

[20] M. Yin, G. Li, M. Zhou, and C. Zhao, "Modeling of the Wind Turbine with a Permanent Magnet Synchronous Generator for Integration", In: Proc. of 2007 IEEE Power Engineering Society
General Meeting, pp. 1-6, 2007.

[21] A. Rolan, A. Luna, G. Vazquez, D. Aguilar, and G. Azevedo, "Modeling of a variable speed wind turbine with a Permanent Magnet Synchronous Generator", In: Proc. of 2009 IEEE International Symposium on Industrial Electronics, pp. 734-739, 2009.

[22] Y. Zou and J. He, "Comprehensive modeling, simulation and experimental validation of Permanent Magnet Synchronous generator wind power system", In: Proc. of 2016 IEEE/IAS 52nd Industrial and Commercial Power Systems Technical Conference (I\&CPS), pp. 1-9, 2016.

[23] C. F. Lu, C. C. Liu, and C. J. Wu, "Dynamic modelling of battery energy storage system and application to power system stability", IEE Proceedings-Generation, Transm. Distrib., Vol. 142, No. 4, pp. 429-435, 1995.

[24] P. Prajapati and A. Parmar, "Multi-area Load Frequency Control by various conventional controller using Battery Energy Storage System", In: Proc. of 2016 International Conference on Energy Efficient Technologies for Sustainability (ICEETS), pp. 467-472, 2016, doi: 10.1109/ICEETS.2016.7583800.

[25] S. Gurung, F. Jurado, S. Naetiladdanon, and A. Sangswang, "Comparative analysis of probabilistic and deterministic approach to tune the power system stabilizers using the directional bat algorithm to improve system small-signal stability", Electr. Power Syst. Res., Vol. 181, p. 106176, 2020.

[26] Y. Shen, W. Yao, J. Wen, H. He, and L. Jiang, "Resilient Wide-Area Damping Control Using GrHDP to Tolerate Communication Failures", IEEE Trans. Smart Grid, p. 1, 2018, doi: 10.1109/TSG.2018.2803822.

[27] T. Surinkaew and I. Ngamroo, "Hierarchical CoOrdinated Wide Area and Local Controls of DFIG Wind Turbine and PSS for Robust Power Oscillation Damping", IEEE Trans. Sustain. Energy, Vol. 7, No. 3, pp. 943-955, 2016, doi: 10.1109/TSTE.2015.2508558.

[28] L. Zhou et al., "Damping Inter-Area Oscillations With Large-Scale PV Plant by Modified Multiple-Model Adaptive Control Strategy", IEEE Trans. Sustain. Energy, Vol. 8, No. 4, pp. 1629-1636, 2017, doi: 10.1109/TSTE.2017.2697905.

[29] H. Setiadi, N. Mithulananthan, and R. Shah, "Design of wide-area POD with resiliency using modified DEA for power systems with high penetration of renewable energy", IET Renew. Power Gener., Vol. 13, No. 2, pp. 342-351, 2018. 
[30] M. Djukanovic, M. Khammash, and V. Vittal, "Application of the structured singular value theory for robust stability and control analysis in multimachine power systems. I. Framework development", IEEE Trans. Power Syst., Vol. 13, No. 4, pp. 1311-1316, 1998. 